\title{
Proceeding
}

8th INSHS International Christmas Sport Scientific Conference, 5-7 December 2013. International Network of Sport and Health

Science. Szombathely, Hungary

\section{Swimming training and pulmonary variables in women}

\author{
GÜLSÜN AYDIN , ISMAIL KOCA \\ Anadolu University, Sport Faculty, Eskişehir, Turkey
}

\begin{abstract}
Aydin, G. \& Koca, I. (2014). Swimming training and pulmonary variables in women. J. Hum. Sport Exerc., 9(Proc1), pp.S474-S480. Most spirometry testing is done for patients with pulmonary problems not for general population samples (Enright et al., 2004) and not for the effect of training. Evaluation of the effect of exercise on diffusing capacity would be helpful to evaluate the ability of the pulmonary capillary bed to expand and increase its capacity to transfer gas during exercise (Wang, 2004). The purpose of this study was therefore to examine the effects of swimming technical skill training on pulmonary variables such as FVC (forced vital capacity), FEV1 (forced expiratory volume in one second), FEF25-75 (forced expiratory flow from 25\% to 75\%), MVV (maximal voluntary ventilation), ERV (expiratory reserve volume), VC (vital capacity), PEF (peak expiratory flow) in women. Nineteen women (swimming trained group $=11$, control inactive group $=8$ ) participated in this study. All the subjects with the exception of inactive control group participated in swimming technical skill training, three times a week for 12 weeks. Measurements were made before and after the swimming training for each subject with spirometer (Sensormedics Vmax $29 \mathrm{C}$ ). The swimming training program was designed on the basis of swimming skills including: breathing in water, sliding the body in water, free style and backstroke foot drills, arm-foot and breathing coordination drills with and without swimming board, free style and backstroke drills. It was found that swimming has a positive effect on FVC (forced vital capacity), FEV1 (forced expiratory volume in one second), MVV (maximal voluntary ventilation) (Akgün, 1986). According Khosravi et al. (2013) endurance training combined with resistance training has greater effect on VC, FVC, FEF rating at 25\%-75\%, and also on PEF except MVV. The following variables exhibited significant difference after the 3 months swimming technical skill training: MVV and PEF. Results indicated that swimming technical skill training during 12 weeks training had a significantly positive effect on pulmonary variables such as MVV, PEF but no significant changes were observed in FVC, FEV1, FEF \%25-75, ERV, VC. Efficacy of respiratory and pulmonary functions has a direct relationship with general health. Exercise training improves endurance and strength of athletes' respiratory muscles; it also causes resistance reduction in respiratory canals, and increases lung elasticity and alveolar expansion as studies have supported the expansion of pulmonary volumes and capacities (Khosravi et al., 2013). As a conclusion of the present study suggest that swimming technical skill training can improve pulmonary function of women. According to a study (Armour et al., 1993) the increased lung volumes in swimming were not due to an increase in alveolar distensibility and may, therefore, have been due to an increased alveolar number. Our study was conducted in healthy subjects. In the future, it may be of value to investigate the effects of the swimming in people who have airway problems or the other health problems like obesity and also in athletes. Key words: TECHNICAL SKILL, SPIROMETRY, TRAINING EFFECT, TRAINED WOMEN.
\end{abstract}

Corresponding author. Anadolu University, Sport Faculty, Eskişehir, Turkey.

E-mail: gaydin@anadolu.edu.tr

8th INSHS International Christmas Sport Scientific Conference, 5-7 December 2013. International Network of Sport and Health Science. Szombathely, Hungary.

JOURNAL OF HUMAN SPORT \& EXERCISE ISSN 1988-5202

(c) Faculty of Education. University of Alicante

doi:10.14198/jhse.2014.9.Proc1.35

VOLUME 9 | Proc1 | 2014 | S474 


\section{INTRODUCTION}

Beneficial effect is seen on various systems of the body due to any type of exercise by way of improving their functions if performed regularly. Swimming one of the best exercises for maintaining physical fitness and proper health and have a profound effect on the lung function of an individual (Sable et al., 2012).

In swimming, breathing patterns and breath frequency is important, as it is one sport which has intermittent periods of hypoxia (http-1). Swimming engages practically all muscle groups. Hence $\mathrm{O} 2$ utilization for the muscle is higher in swimmers. The water pressure on the thorax makes the respiration difficult. Mechanics of breathing involved in different strokes of swimmers varies with each strokes. Lung function status in swimming plays a key role in their performance (Kesavachandran et al., 2001).

The inclusion of spirometry as a routine test, especially in patients at risk of respiratory disease, will lead to earlier detection of respiratory disease and more effective intervention and treatment (Burton et al., 2011). Most spirometry testing is done for patients with pulmonary problems not for general population samples (Enright et al., 2004) and not for the effect of training.

Evaluation of the effect of exercise on diffusing capacity would be helpful to evaluate the ability of the pulmonary capillary bed to expand and increase its capacity to transfer gas during exercise (Wang, 2004). The purpose of this study was therefore to examine the effects of swimming technical skill training on pulmonary variables such as FVC (forced vital capacity), FEV1 (forced expiratory volume in one second), FEF25-75 (forced expiratory flow from 25\% to 75\%), MVV (maximal voluntary ventilation), ERV (expiratory reserve volume), VC (vital capacity), PEF (peak expiratory flow) in women.

\section{MATERIAL AND METHODS}

\section{Participants}

Nineteen women (swimming trained group $=11$, control inactive group $=8$ ) who had a swimming technical skill education and training program participated in this study. All the subjects were informed about the testing protocols and signed an informal consent.

All the subjects with the exception of inactive control group participated in swimming technical skill training, three times a week for 12 weeks in Anadolu University swimming pool. The swimming training program was designed on the basis of swimming skills including:
1. Adaptation to water,
2. Expiring in water,
3. Inspiring out of water and expiring in water,
4. Controlling the body in a horizontal position on water,
5. Sliding the body in water,
6. Arm and breathing coordination drills with swimming board,
7. Foot and breathing coordination drills with swimming board,
8. Arm and breathing coordination drills without swimming board,
9. Foot and breathing coordination drills without swimming board,
10. Free style foot drills,
11. Backstroke foot drills,
12. Free style and backstroke technical drills. 


\section{Anthropometric Measurements}

Height and weight were measured with Seca electronic height and weight measuring machine. Circumference measurements were made with Seca ergonomic circumference measuring tape and skinfold thickness measurements were made with Holtain skinfold caliper to estimate BMI, \%FM, FFM, FM, total skinfold. The measurements were taken from the right of the body three times the mean of the value was taken for the calculations. Açıkada formula was used to calculate the $\% \mathrm{FM}$.

\section{Lung Volumes Test}

The spirometric tests were performed in Osmangazi University, Department of Physiology, Exercise Physiology Laboratory. Pre-measurements and post-measurements were made before and after the swimming training for each subject with spirometer (Sensormedics Vmax $29 \mathrm{C}$ ). The following lung volumes were selected for the study: FVC (forced vital capacity), FEV1 (forced expiratory volume in one second), FEF25-75 (forced expiratory flow from 25\% to 75\%), MVV (maximal voluntary ventilation), ERV (expiratory reserve volume), VC (vital capacity), PEF (peak expiratory flow).

The spirometer calibration was made and the knowledge of each subject (age, height, weight) was recorded before the test. The knowledge was given about the position of mouthpiece, nose clip and about the test procedure by telling and practicing. Tests were performed in the vertical sitting position on a 60 centimeter chair without standing up and with nose clipped. Tests were also performed that the right arm position was in 1500 - 1600 flexion by holding mouthpiece. Subjects were motivated by verbal commands to take best lung volume values of them. Test measurements were repeated 3-6 times and were taken the best lung volume value.

\section{Statistical Analyses}

SPSS was used for statistical analysis of data. . Statistical analysis for the realization of the significance level was adopted at .05. Paired T test was used for comparison of the pre-measurement and postmeasurement values.

\section{RESULTS}

The results of this study about physical characteristics of control group and swimming trained group are summarized in table 1 and table 2.

- As seen on table 1 there is no significant difference on physical characteristics (body mass, BMI, $\% F M, F F M, F M$, total skinfold) of control group after three months period and there is no significant difference on physical characteristics of trained group after three month swimming technical skill training $(p>0,05)$.

- Mean values, standart deviation and $p$-values of spirometric predictors of control group and trained group are shown in Table 3 and Table 4.

- According to table 3, there is no statistically difference between before and after three months values of control group's lung volumes $(p>0,05)$ (Table 3$)$. 
Table 1. Physical Characteristics of Control Group

\begin{tabular}{lcccc}
\hline \multirow{2}{*}{ Physical Characteristics } & \multicolumn{3}{c}{ Before 3 months } & After 3 months \\
\cline { 2 - 5 } & $\mathbf{n}$ & $\mathbf{X} \pm$ S.D. & $\mathbf{X} \pm$ S.D. & $\mathbf{p}$ \\
\hline Age (year) & 8 & $21,75 \pm 1,28$ & $21,75 \pm 1,28$ & - \\
Height (cm) & 8 & $158,31 \pm 2,78$ & $158,49 \pm 2,57$ & - \\
Body mass (kg) & 8 & $59,95 \pm 9,66$ & $59,76 \pm 9,32$ & - \\
BMI (kg/m²) & 8 & $23,73 \pm 3,37$ & $23,70 \pm 3,29$ & - \\
FM (\%) & 8 & $29,92 \pm 4,42$ & $29,76 \pm 4,43$ & - \\
FFM (kg) & 8 & $41,69 \pm 4,50$ & $41,70 \pm 4,57$ & - \\
FM (kg) & 8 & $18,26 \pm 5,60$ & $18,06 \pm 5,37$ & - \\
Total skinfold (mm) & 8 & $61,83 \pm 11,54$ & $61,78 \pm 11,08$ & - \\
\hline
\end{tabular}

Table 2. Physical Characteristics of Swimming Trained Group

\begin{tabular}{lcccc}
\hline \multirow{2}{*}{ Physical Characteristics } & & $\begin{array}{c}\text { Before 3 months swimming } \\
\text { technical skill training }\end{array}$ & $\begin{array}{c}\text { After 3 months swimming } \\
\text { technical skill training }\end{array}$ & \\
\cline { 2 - 5 } & $\mathbf{n}$ & $\mathbf{X} \pm$ S.D. & $\mathbf{X} \pm$ S.D. & $\mathbf{p}$ \\
\hline Age (year) & 11 & $21,36 \pm 1,43$ & $21,36 \pm 1,43$ & - \\
Height (cm) & 11 & $160,81 \pm 5,41$ & $160,91 \pm 5,21$ & - \\
Body mass (kg) & 11 & $54,05 \pm 6,58$ & $54,96 \pm 6,38$ & - \\
BMl (kg/m2) & 11 & $20,84 \pm 2,28$ & $21,17 \pm 2,19$ & - \\
FM (\%) & 11 & $22,52 \pm 4,48$ & $22,36 \pm 3,66$ & - \\
FFM (kg) & 11 & $41,86 \pm 5,63$ & $42,72 \pm 5,73$ & - \\
FM (kg) & 11 & $12,18 \pm 2,89$ & $12,24 \pm 2,28$ & - \\
Total skinfold (mm) & 11 & $55,09 \pm 11,24$ & $54,52 \pm 11,45$ & - \\
\hline
\end{tabular}

Table 3. Spirometric Predictors of Control Group.

\begin{tabular}{lcccc}
\hline \multirow{2}{*}{ Sirometric Predictors } & \multicolumn{3}{c}{ Before 3 months } & After 3 months \\
\cline { 2 - 5 } & $\mathbf{n}$ & $\mathbf{X} \pm$ SD & $\mathbf{X} \pm$ SD & $\mathbf{p}$ \\
\hline FVC (liter) & 8 & $3,85 \pm 0,49$ & $3,74 \pm 0,47$ & - \\
FEV1 (liter) & 8 & $3,32 \pm 0,33$ & $3,24 \pm 0,41$ & - \\
FEF \%25-75 (I/sec.) & 8 & $3,87 \pm 0,88$ & $3,77 \pm 0,87$ & - \\
MVV (I/min) & 8 & $130,25 \pm 3,41$ & $130,13 \pm 3,60$ & - \\
ERV (liter) & 8 & $1,16 \pm 0,58$ & $0,97 \pm 0,57$ & - \\
VC (litre) & 8 & $4,08 \pm 0,44$ & $3,98 \pm 0,87$ & - \\
PEF (l/sec.) & 8 & $5,46 \pm 0,79$ & $5,47 \pm 0,69$ & - \\
\hline
\end{tabular}


Table 4. Spirometric Predictors of Trained Group

\begin{tabular}{lcccc}
\hline \multirow{2}{*}{ Spirometric Predictors } & \multicolumn{3}{c}{$\begin{array}{c}\text { Before 3 months swimming } \\
\text { technical skill training }\end{array}$} & $\begin{array}{c}\text { After 3 months swimming } \\
\text { technical skill training }\end{array}$ \\
\cline { 2 - 5 } & $\mathbf{n}$ & $\mathbf{X} \pm$ S.D. & $\mathbf{X} \pm$ S.D. & $\mathbf{p}$ \\
\hline FVC (liter) & 11 & $3,69 \pm 0,48$ & $3,75 \pm 0,27$ & - \\
FEV1 (liter) & 11 & $3,12 \pm 0,44$ & $3,17 \pm 0,31$ & - \\
FEF \%25-75 (I/sec.) & 11 & $3,48 \pm 1,13$ & $3,67 \pm 0,95$ & - \\
MVV (I/min) & 11 & $133,45 \pm 17,31$ & $140,73 \pm 16,35$ & $*$ \\
ERV (liter) & 11 & $0,83 \pm 0,43$ & $0,95 \pm 0,44$ & - \\
VC (litre) & 11 & $3,78 \pm 0,47$ & $3,96 \pm 0,37$ & - \\
PEF (I/sec.) & 11 & $4,91 \pm 1,22$ & $5,99 \pm 0,83$ & $*$ \\
\hline
\end{tabular}

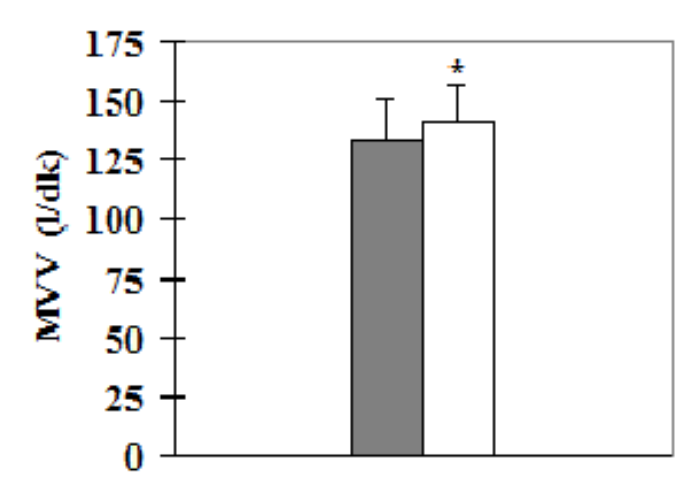

Trained Group (Before 3 months swimming technical skill training)

Trained Group (After 3 months swimming technical skill training)

Figure 1. The effect of 3 months swimming technical skill training on MVV of trained women ( $\left.{ }^{*} p<0,05\right)$

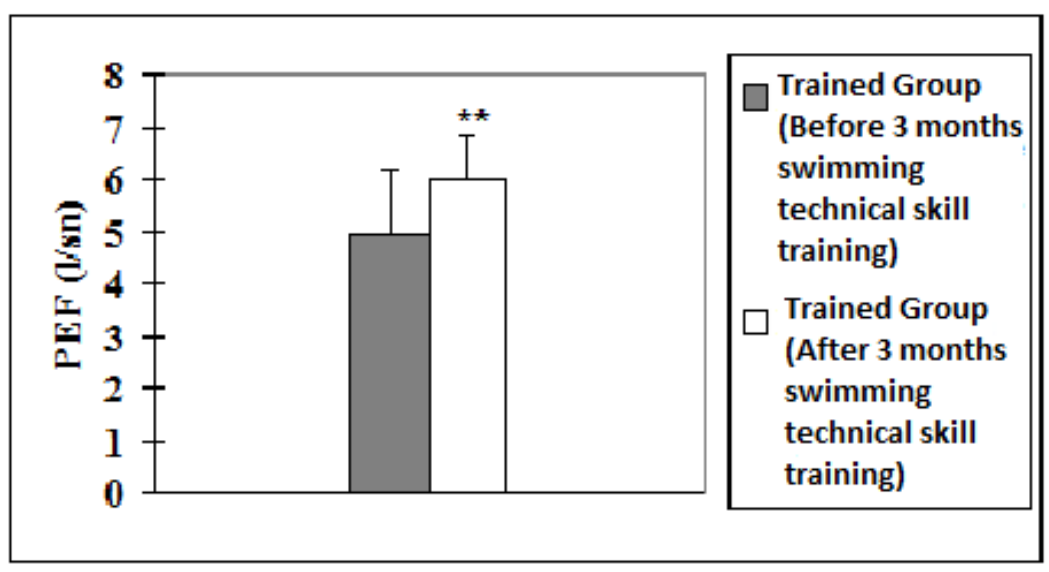

Figure 2. The effect of 3 months swimming technical skill training on PEF of trained women $\left({ }^{* *} p<0,01\right)$ 
As seen in table 4, there is no significant difference between before and after three months values of FVC, FEV1, FEF \%25-75, ERV, VC but there is a significant difference between values of MVV $(p=0,024)$ and PEF $(p=0,003)$. As observed in the lung volumes (MVV and PEF) showed higher values after the three weeks swimming skill training.

\section{DISCUSSION}

Efficacy of respiratory and pulmonary functions has a direct relationship with general health. Exercise training improves endurance and strength of athletes' respiratory muscles; it also causes resistance reduction in respiratory canals, and increases lung elasticity and alveolar expansion as studies have supported the expansion of pulmonary volumes and capacities (Khosravi et al., 2013).

In general it was admitted that swimming have a positive effect on FVC (forced vital capacity), FEV1 (forced expiratory volume in one second), MVV (maximal voluntary ventilation) (Akgün, 1986). Khosravi et al. (2013) stated that endurance training combined with resistance training has greater effect on VC, FVC, FEF rating at 25\%-75\%, PEF except MVV. Also the VC, FEV1 were found higher in swimmers in another study (Newmann et al., 1961). The restricted ventilation experienced during swimming leads the swimmers to face intermittent hypoxia. This may result in alveolar hyperplasia and thus increased TV (Tidal volume), FVC and FEV1 (Astrand et al., 1963). According to another research results indicated that swimming has considerable effect on enhancing lung functions of an individual as FVC, FEV1, PEF were significantly raised in swimmers after swimming session (Mehrotra et al., 1997).

Otherwise according to our study, the following variables exhibited significant difference after the 3 months swimming technical skill training: MVV (maximal voluntary ventilation) and PEF (peak expiratory flow). Results indicated that swimming technical skill training during 12 weeks training had a significantly positive effect on pulmonary variables such as MVV, PEF but no significant changes were observed in FVC, FEV1, FEF \%25-75, ERV, VC.

Overall, the improvements may stem from many factors as water resistance increasing the strength of the inspiratory muscles, brief periods of not breathing improving the tension of the inspiratory muscles, hypoxia may also increase the metabolic stress of the muscles (Silvatti et al., 2012). During swimming the external pressure is high therefore the respiratory muscles along with diaphragm develop greater pressure for respiration. This leads to improvement in the functional capacity of these muscles. Swimming increases this ability by number of factors. It involves keeping the head extended which is constant exercise of erector spinae muscle which increases antero-posterior diameter of the lungs. The sterenocleidomastoid, trapzius and diaphragm are being constantly exercised (Sable et al., 2012). Long periods of intensive swim training may increase volume variations in the abdominal region and more coordination among compartments involved in forces respiratory tasks (Silvatti et al., 2012).

Swimming exercise affects lung volume measurements as respiratory muscles including diaphragm of swimmers are required to develop greater pressure as a consequence of immersion in water during respiratory cycle, thus may lead to functional improvement in these muscles and also alterations in elasticity of lung and chest wall or of ventilatory muscles, leading to an improvement in forced vital capacity and other lung functions of swimmers (Sable et al., 2012). In the light of an another study (Armour, et. al, 1993) the increased lung volumes in swimming were not due to an increase in alveolar distensibility and may, therefore, have been due to an increased alveolar number. 


\section{CONCLUSIONS}

As a conclusion of the present study suggest that swimming technical skill training can improve pulmonary function of women. This study suggests that regular three month swimming training has a positive role in improving lung volumes. As Mehrotra et al. (1997), we may suggest swimming to include in the exercise programme for rehabilitation of respiratory patients who have airway or lung function problems, for increasing quality of life according to our study results.

Our study was conducted on healthy subjects. In the future, it may be of value to investigate the effects of the swimming in people who have airway problems or other health problems like obesity and also in athletes.

\section{REFERENCES}

1. Akgün, N. (1986). Egzersiz Fizyolojisi. Bornova, İzmir: Ege Üniversitesi Basımevi, 135.

2. Armour, J., Donnelly, P.M. \& Bye, P.T.P. (1993). The large lungs of elite swimmers: an increased alveolar number? Eur Respir J., 6, pp.237-247.

3. Astrand, P.O., Engstrom, B.O., Eriksson, P. \& Karlberg, J. (1963). Girl swimmers. Acta Paediat Suppl. 147, pp.3-75.

4. Burton, D., Johns, D.P. \& Swanney, M.P. (2011). Spirometer Users' And Buyers' Guide.

5. Enright, P.L., Beck, K.C. \& Sherrill, D.L. (2004). Repeatability of spirometry in 18,000 adult patients. Am J Respir Crit Care Med. 169(2), pp.235-238.

6. Http://www.swimmingscience.net/2013/10/swimming-increases-diaphragmstrength.

7. Kesavachandran, C., Nair, H.R. \& Shashidhar, S. (2001). Lung volumes in swimmers performing different styles of swimming. Indian Journal of Medicine Science. 55(12), pp.669-676.

8. Khosravi, M., Tayebi, S.M. \& Safari, H. (2013). Single and concurrent effects of endurance and resistance training on pulmonary function. Iranian Journal of Basic Medical Sciences. 16, pp.62834.

9. Newman, F., Smalley, B.F. \& Thomson, M.L. (1961). A comparison between body size and lung function of swimmers and normal school children. J. Applied Physiol. 156, pp.9-10.

10. Sable, M., Vaidya, S.M. \& Sable, S.S. (2012). Comparative study of lung functions in swimmers and runners. Indian Journal Physiol Pharmacol. 56(1), pp.100-4.

11. Silvatti, A.P., Sarro, K.J, Cerveri, P. \& Baron, G. (2012). A 3D kinematic analysis of breathing patterns in competitive swimmers. Journal of Sports. 30(14), pp.1551-1560.

12. Tartibiana, B., Malekia, B.H. \& Abbasib, A. (2010). The effects of omega-3 supplementation on pulmonary function of young wrestlers during intensive training. Journal of Science and Medicine in Sport. 13(2), pp. 281-286.

13. Wang, J.S. (2004). Pulmonary function tests in preoperative pulmonary evaluation. Respir. Med. 98(7), pp. 598-605. 